\title{
Polymorphisms in miRNA binding site: new insight into small cell lung cancer susceptibility
}

\author{
Hong-yu LIU, Jun CHEN*
}

Acta Pharmacologica Sinica (2011) 32: 1191-1192; doi: 10.1038/aps.2011.124; published online 29 Aug 2011

L ung cancer is a leading cause in ${ }_{c}$ cancer-related deaths with less than $15 \%$ five-year survival worldwide. Small cell lung cancer (SCLC), which accounts for about $15 \%-18 \%$ of lung cancer, carries the worst prognosis within the lung cancer patients. SCLC differs from other lung cancers, so called nonsmall cell lung cancers (NSCLCs), in the specifically clinical and biologic characteristics. It exhibits aggressive behavior, with rapid growth, early spread to distant sites. Although exquisite sensitive to chemotherapy and radiation, SCLC recurs rapidly with only $5 \%$ of patients surviving five years and frequent association with distinct paraneoplastic syndromes $^{[1]}$.

The predominant cause of SCLC is tobacco smoking, and there is increasing information concerning molecular abnormalities involved in the pathogenesis of SCLC. Although it was proved that dominant oncogenes of the Myc family are frequently overexpressed in SCLC ${ }^{[2,3],}$ and the tumor suppressor genes (TSGs) p53 and retinoblastoma TSG are mutated and inactivated in more than $90 \%$ of SCLC ${ }^{[4-6]}$, little is known about the genetic factors associated with the development of SCLC.

Tianjin Key Laboratory of Lung Cancer Metastasis and Tumor Microenvironment; Tianjin Lung Cancer Institute; Tianjin Medical University General Hospital; Tianjin 300052, China

* Correspondence: Jun CHEN

(huntercj2004@yahoo.com)
CYP1A1 gene polymorphisms were reported to increase lung cancer risk in a high incidence region of Spain and the Thr461Asn polymorphism was associated with SCLC ${ }^{[7]}$. NQO1 protein may be involved in detoxification of free quinone which is associated with the development of SCLC. It was found in a UK population that individuals with reduced activity of the enzyme, due to a polymorphism of this gene, may increase the risk in developing the disease ${ }^{[8]}$. However, the genetic factors regulated by microRNAs (miRNAs) in development of SCLC are unclear.

miRNAs are a class of small noncoding RNA molecules that regulate gene expression through binding the 3'untranslated region (3'UTR) of mRNAs of target genes, resulting in mRNA cleavage or translation repression. It is estimated that about $30 \%$ of human genes are regulated by miRNAs ${ }^{[9]}$. As a result, miRNAs may regulate the expressions of proto-oncogenes or tumor suppressor genes, thus play important roles in tumorigenesis. Increasing evidence demonstrates that polymorphisms (SNPs) in the 3'UTR of genes targeted by miRNAs can disturb or obstruct miRNAs binding and consequentially influence regulation of the target genes, which might be associated with susceptibility to certain diseases including cancer. Xiong et $a l^{[10]}$ recently identified SNPs within the $3^{\prime}$ UTR of miRNA genes deregulated in human SCLC, and inves- tigated their associations with SCLC susceptibility in 666 patients with SCLC and 758 controls in a Chinese population ${ }^{[10]}$. They found that the SNP rs3134615 located in the 3'UTR of the L-MYC gene MYCL1 and the rs3134615T allele were associated with the significantly increased risk of SCLC, with the OR for carrying the GT or TT genotype being 2.08 (95\% CI, 1.39-3.21; $P=0.0004$ ), as compared to the GG genotype. Reporter gene assays showed that MYCL1 was the target of hsa-miR-1827, which negatively regulates MYCL1 expression. The rs3134615 G to $\mathrm{T}$ change may inhibit the interaction of hsa-miR-1827 with MYCL1 3'UTR, resulting in higher constitutive expression of MYCL1. Because MYCL1 is a member of MYC oncogene family that play a critical role in carcinogenesis, individuals carrying the rs3134615 T allele would be expected to have elevated risk for the development of SCLC.

The results of Xiong et al provide a new insight into SCLC tumorigenesis and have potential implication in early detection and target treatment of SCLC.

1 van Meerbeeck JP, Fennell DA, De Ruysscher DK. Small-cell lung cancer. Lancet 2011 doi:10.1016/ S0140-6736(11)60165-7.

2 Johnson BE, Russell E, Simmons AM, Phelps R, Steinberg SM, Inde DC, et al. MYC family DNA amplification in 126 tumor cell lines from patients with small cell lung cancer. J Cell Biochem Suppl 1996; 24: 210-7.

3 Rygaard K, Vindeløv LL, Spang-Thomsen M. 
Expression of myc family oncoproteins in small-cell lung-cancer cell lines and xenografts. Int J Cancer 1993; 54: 144-52.

4 Lohmann D, Pütz B, Reich U, Böhm J, Präuer H, Höfler $\mathrm{H}$. Mutational spectrum of the p53 gene in human small-cell lung cancer and relationship to clinicopathological data. Am J Pathol 1993; 142: 907-15.

5 Jacobson DR, Fishman CL, Mills NE. Molecular genetic tumor markers in the early diagnosis and screening of non-small-cell lung cancer. Ann Oncol
1995; 6: S3-8.

6 Wistuba II, Gazdar AF, Minna JD.Molecular genetics of small cell lung carcinoma. Semin Oncol 2001; 28: 3-13.

7 San Jose C, Cabanillas A, Benitez J, Carrillo JA, Jimenez M, Gervasini G. CYP1A1 gene polymorhisms increase lung cancer risk in a high-incidence region of Spain: a case control study. BMC Cancer 2010; 10: 463.

8 Lewis SJ, Cherry NM, Niven RM, Barber PV, Povey AC. Polymorphisms in the $\mathrm{NAD}(\mathrm{P}) \mathrm{H}$ : quinone oxidoreductase gene and small cell lung cancer risk in a UK population. Lung Cancer 2001; 34: 177-83.

9 Winter J, Diederichs S. MicroRNA biogenesis and cancer. Methods Mol Biol 2011; 676: 3-22.

10 Xiong F, Wu C, Chang J, Yu D, Xu B, Yuan P, et al. Genetic variation in an miRNA-1827 binding site in MYCL1 alters susceptibility to small cell lung cancer. Cancer Res 2011; 71: 5175-81. 